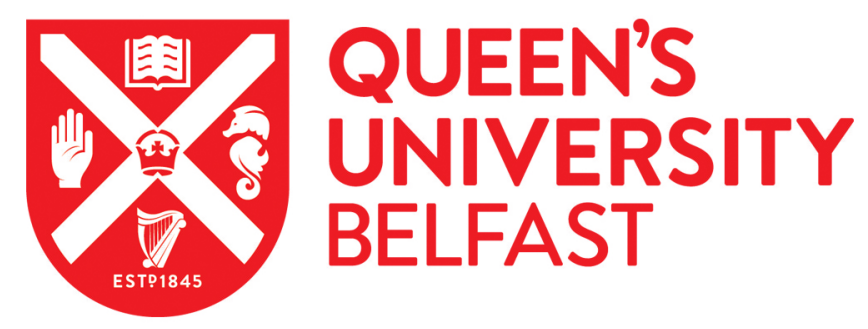

\title{
Teachers' influence on purchase and wear of children's glasses in rural China: the PRICE study
}

Wang, X., Ma, Y., Hu, M., Jin, L., Xiao, B., Ni, M., Yi, H., Ma, X., Wang, C., Varga, B., Huang, Y., Rozelle, S., \& Congdon, N. (2018). Teachers' influence on purchase and wear of children's glasses in rural China: the PRICE study. Clinical and Experimental Ophthalmology. https://doi.org/10.1111/ceo.13376

Published in:

Clinical and Experimental Ophthalmology

Document Version:

Peer reviewed version

Queen's University Belfast - Research Portal:

Link to publication record in Queen's University Belfast Research Portal

Publisher rights

Copyright 2018 Wiley. This work is made available online in accordance with the publisher's policies. Please refer to any applicable terms of use of the publisher.

\section{General rights}

Copyright for the publications made accessible via the Queen's University Belfast Research Portal is retained by the author(s) and / or other copyright owners and it is a condition of accessing these publications that users recognise and abide by the legal requirements associated with these rights.

Take down policy

The Research Portal is Queen's institutional repository that provides access to Queen's research output. Every effort has been made to ensure that content in the Research Portal does not infringe any person's rights, or applicable UK laws. If you discover content in the Research Portal that you believe breaches copyright or violates any law, please contact openaccess@qub.ac.uk. 
Teachers' influence on purchase and wear of children's glasses in rural China: the PRICE study

Xiuqin Wang, $\mathrm{PhD},{ }^{1,2}$ Yue Ma, MPA $,{ }^{3} \mathrm{Min} \mathrm{Hu}, \mathrm{MD},{ }^{4}$ Ling Jin, $\mathrm{MS},{ }^{2}$ Baixiang Xiao, $\mathrm{MM},{ }^{2}$ Ming Ni, BM, ${ }^{5}$ Hongmei Yi, PhD,${ }^{6}$ Xiaochen Ma, PhD,${ }^{7}$ Congyao Wang, MD, ${ }^{2}$ Beatrice Varga, $\mathrm{MPH},{ }^{8}$ Yiwen Huang, $\mathrm{MS},{ }^{5}$ Scott Rozelle, $\mathrm{PhD},{ }^{9}$ and Nathan Congdon, $\mathrm{MD}^{2,10,11}$

1. Affiliated Hospital of Guangdong Medical University, Zhanjiang, Guangdong, China.

2. State Key Laboratory of Ophthalmology and Division of Preventive Ophthalmology, Zhongshan Ophthalmic Center, Sun Yat-sen University, Guangzhou, Guangdong, China.

3. The Center for Experimental Economics in Education, Shaanxi Normal University, Xi'an, Shaanxi, China

4. The Second People's Hospital of Yunnan Province, Kunming, Yunnan, China.

5. The Fred Hollows Foundation China Project, Kunming, Yunnan, China.

6. Center for Chinese Agricultural Policy, Institute of Geographical Sciences and Natural Resources Research, Chinese Academy of Sciences, Beijing, China.

7. China Center for Health Development Studies, Peking University, Beijing, China.

8. The Fred Hollows Foundation Australia, Sydney, Australia.

9. Freeman Spogli Institute of International Studies, Stanford University, Palo Alto, USA

10. Orbis International, New York, NY, United States.

11. Translational Research for Equitable Eyecare, Centre for Public Health, Queen's University Belfast, Belfast N. Ireland

Correspondence: Nathan Congdon, State Key Laboratory of Ophthalmology and Division of Preventive Ophthalmology, Zhongshan Ophthalmic Center, Sun Yat-sen University, Guangzhou, People's Republic of China 510060; and Translational Research for Equitable Eyecare, Center for Public Health, Queen's University Belfast, Royal Victoria Hospital, Institute for Clinical Sciences Block B, 274 Grosvenor Rd, Belfast N. Ireland BT27 5NF; ncongdon1@gmail.com. Telephone numbers: 862087682342 
Category of manuscript: Epidemiology

Running head: Teachers' influence on children's glasses in China

Funding: The Fred Hollows Foundation; Orbis International; US Agency for International Development; Luxottica-China (Shanghai); Essilor-China(Shanghai); Prof Congdon is supported by the Chinese government's Thousand Man Plan and by the Ulverscroft Foundation.

Conflicts of Interest: The free glasses used in this study were supplied by OneSight, Luxottica-China, and Essilor-China, producers of frames and lenses in China. The authors have no other financial relationships with any organisations that might have an interest in the submitted work in the previous three years; and no other relationships or activities that could appear to have influenced the submitted work.

Length: MS: 2970 Words, 4 Tables, Abstract: 250 words

Version: 21 February 2018 


\begin{abstract}
Importance: Uncorrected refractive error accounts for $90 \%$ of poor vision among Chinese children.

Background: Teachers impact children's behavior, but little is known about their influence on children's glasses wear.
\end{abstract}

Design: Cohort study.

Participants: Children at 138 randomly-selected primary schools in Guangdong and Yunnan provinces, China, with uncorrected visual acuity (VA) $<=6 / 12$ in either eye correctable to $>6 / 12$ in both eyes, and their teachers.

Methods: Teachers and children underwent VA testing and completed questionnaires about their spectacles use and attitudes towards children's vision. Children's acceptance of free glasses was recorded, and spectacle purchase and wear were assessed 6 months later.

Results: A total of 882 children (mean age 10.6 years, $45.5 \%$ boys) and 276 teachers (mean age 37.9 years, $67.8 \%$ female) participated. Among teachers, $20.4 \%(56 / 275)$ believed glasses worsened children's vision, $68.4 \%$ (188/275) felt eye exercises prevented myopia, 55.0\% (151/275) thought children with moderate myopia shouldn't wear glasses, and 93.1\% (256/275) encouraged children to obtain glasses. Teacher 
factors associated with children's glasses use included believing glasses harm children's vision (decreased purchase: relative risk (RR) 0.65, 95\% CI 0.43, 0.98, $\mathrm{P}<0.05$ ); supporting children's classroom glasses wear (increased glasses wear: RR 2.20, 95\% CI $1.23,3.95, \mathrm{P}<0.01$ ); and advising children to obtain glasses (increased free glasses acceptance: RR 2.74, 95\% CI 1.29, 5.84, P < 0.01; increased wear RR 2.93, 95\% CI $1.45,5.90, \mathrm{P}<0.01)$, but not teacher's ownership/wear of glasses.

Conclusions: Though teachers had limited knowledge about children's vision, they strongly influenced children's glasses uptake.

Key Words: Teacher, myopia, glasses, children, rural, China 


\section{Introduction}

There are 13 million children in the world visually-impaired from under-corrected refractive error (URE), and among them almost half live in China. ${ }^{1}$ URE accounts for $>$ $90 \%$ of visual disability among rural Chinese children. ${ }^{2,3}$ Glasses correction is a safe ${ }^{4}$ and effective means for treatment of URE, and has been demonstrated to improve children's educational outcomes, ${ }^{5}$ but only $15-20 \%$ of Chinese rural ${ }^{5}$ and urban migrant ${ }^{6}$ children who need glasses have them.

Many reasons exist for this situation. Refractionists practicing in rural China are minimally trained, ${ }^{7}$ and together with existing optical dispensing services, frequently deliver spectacles whose power is not accurate. ${ }^{8}$ A number of stakeholders, including children, families and teachers, believe incorrectly that wearing glasses will harm children's eyes, ${ }^{9,10}$ despite randomized trial evidence proving spectacles are safe for children's vision. ${ }^{4}$

It has been shown that rural Chinese teachers can accurately perform vision screening for children with only modest training, ${ }^{11}$ and incentivizing teachers can significantly improve urban migrant children's rates of classroom spectacle use. ${ }^{12}$ Given the potentially-important role of teachers in children's spectacle delivery programs, further study of their influence on the purchase and wear of children's glasses is needed in the 
more typical setting where formal teacher incentives are not used.

We carried out a cluster-randomized, controlled trial in rural Guangdong and Yunnan Provinces, China, to evaluate the impact of giving free glasses on the purchase and use of children's spectacles. During data collection, the head teachers of 276 classes were interviewed about their own spectacle wear, and attitudes and knowledge about children's glasses and vision. The objective of the current paper is to assess the impact of various teacher factors on acceptance of free glasses, purchase of glasses, and children's in-school wear of glasses during the trial. 


\section{Methods}

The protocol for this study has been described elsewhere in detail ${ }^{13}$ and was approved in full by Institutional Review Boards at Stanford University (Palo Alto, USA), the Zhongshan Ophthalmic Center (Guangzhou, China) and Yunnan Red Cross Hospital (Kunming, China). Permission was received from local Boards of Education in each setting, and the principals of all schools and at least one parent provided written informed consent for the participation of each child. The principles of the Declaration of Helsinki were followed throughout.

\section{Setting, Sampling and eligibility criteria}

The study was carried out in Guangdong and Yunnan Provinces, China. Guangdong ranked $9^{\text {th }}$ among China's 31 administrative divisions in per capita Gross Domestic Product in 2014 (US\$ 10,330), while Yunnan was $29^{\text {th }}$ (US\$4438). $1{ }^{14}$ Nine counties or county-level cities were selected, five from Yunnan and four from Guangdong, all having a county-level hospital capable of providing refractive services and willing to participate in the study.

A detailed list of 601 elementary schools in these counties (362 in Guangdong and 239 in Yunnan) was provided by local bureaus of education, including information on the 
number of classes in each school and the number of students per class. Schools with average class sizes $<20$ or $>60$ students ( $19 \%$ of the sample frame) were excluded, because screening at larger schools could not reliably be completed in a day, which would have interfered with the screening schedule, and smaller schools would be expected to have $<7$ children requiring glasses, the minimum number required in our power calculations. From the list of 601 schools, 107 schools (57 in Guangdong and 50 in Yunnan) were randomly selected, with the number of schools selected in each county proportional to population size. An additional 31 schools were randomly selected as above to achieve adequate power for the parent trial, after initial vision screening revealed a lower-than-expected prevalence of refractive error. Thus, a total of 138 schools (88 in Guangdong and 50 in Yunnan) were enrolled. Within each sampled school, one class in each of the fourth and fifth grades (likely age range 9-12 years) were randomly selected, if there was more than one class per grade level. All head teachers of the selected classes were offered the opportunity to take part in the study.

All children in the selected classes meeting the following criteria were considered eligible for the study:

- Uncorrected (without glasses) VA of $\leq 6 / 12$ in either eye correctable to $>6 / 12$ in both eyes with glasses; 
- Refractive error as follows: myopia $\leq-0.75$ diopters (D), hyperopia $\geq 2.00 \mathrm{D}$, or astigmatism (non-spherical refractive error) $\geq 1 \cdot 00 \mathrm{D}^{15}$

\section{Questionnaires}

At baseline (September 2014, beginning of the school year), enumerators administered questionnaires to children, including questions on race (Han versus various minority groups), age, sex, glasses wear, awareness of refractive status, belief that wearing glasses harms children's vision, parental living condition and education, and ownership of a list of 16 selected items as an index of family wealth. At endline (June 2015, end of the school year), student questionnaires were administered on glasses ownership, glasses wear, parental attitude toward wearing glasses and subjective evaluation of project glasses. Information collected on teachers included presenting visual acuity, glasses ownership, and various questions concerning teachers' attitudes and knowledge about children's vision, use of glasses and management of myopia. These were graded on a 5-point Likert scale, from "Strongly agree" to "Strongly disagree".

\section{Visual acuity assessment}

Children and teachers underwent visual acuity screening at school by two trained volunteers. Visual acuity was tested separately for each eye with (if available) and 
without spectacle correction at four m using early treatment diabetic retinopathy study charts ${ }^{15}$ (Precision Vision, La Salle, IL) in a well-lighted, indoor area. If the subject correctly identified the orientation of at least four of five optotypes on the $6 / 60$ line, s/he was examined on the $6 / 30$ line, then the $6 / 15$ line, and then line by line to $6 / 3$. Visual acuity in an eye was defined as the lowest line on which four of five optotypes were read correctly. If the top line could not be read at four $\mathrm{m}$, the participant was tested at one $\mathrm{m}$ and the measured visual acuity was divided by four.

\section{Refraction}

Children with uncorrected visual acuity $\leq 6 / 12$ in either eye underwent cycloplegia with up to three drops of cyclopentolate $1 \%$ in each eye after anesthesia with topical proparacaine hydrochloride $0 \cdot 5 \%$. Children then underwent automated refraction (Topcon KR 8900, Tokyo, Japan) with subjective refinement by an experienced refractionist. Children of parents refusing permission for cycloplegia $(274 / 882=31.1 \%)$ underwent subjective refinement of the non-cycopleged value from the auto-refractor by an experienced refractionist in each eye using a target at four meters distance. Head teachers with presenting visual acuity $<=6 / 12$ in either eye were offered noncyclopleged refraction following the above protocol, and were provided with free glasses if needed.

Randomization and outcome assessment in the parent trial 
In October 2014, after the baseline survey and vision screening but before refraction, eligible children were randomized by school to four groups. The Control group received only a prescription for glasses and a note to the parents suggesting spectacles be purchased. The remaining three groups received either free glasses alone or free glasses with the additional offer of "Upgrade glasses" (having scratchproof lenses and more popular designs based on previous research on the preferences of rural Chinese children) at two different prices. Records at the participating county hospitals were used to determine families' acceptance of free glasses and purchase of upgrade glasses (where provided). Children's self-report on questionnaires at the endline examination provided data on purchase of spectacles outside of the study. At this time, spectacle wear was assessed through unannounced direct examinations.

\section{Statistical methods}

Baseline characteristics of teachers and students were presented as mean (SD, standard deviation) for continuous data with normal distribution, median (IQR, Inter Quartile Range) for continuous data with non-normal distribution and frequency (percentage) for categorical data. Baseline wear of glasses was defined as having glasses at school, having been told to bring them. We calculated family wealth by summing the value, as reported in the China Rural Household Survey Yearbook (Department of Rural Surveys, National Bureau of Statistics of China, 2013), of items on the list of 16 owned by the 
family. Refractive power was defined throughout as the spherical equivalent: the spherical power plus half the cylindrical power. Teachers' knowledge, practices and attitudes about students' myopia and glasses wear were presented as frequencies (percentage). A teacher's knowledge score was defined as the sum of five knowledge items, coded on a Likert scale from 1[“Strongly agree" with a true statement or "Strongly disagree" with a false one] to 5 ["Strongly disagree" with a true statement or "Strongly agree" with a false one]. Thus, the possible range was 5 (Best)-25 (Worst).

Generalized linear models with Poisson regression were used to estimate the relative risk for acceptance of free spectacles, purchase and wear of glasses. All children attending the endline examination were included in the regression analysis for purchase and wear of glasses, while Control group children, who were not offered free glasses, were excluded from the analysis on acceptance of free spectacles. All variables significant at the $\mathrm{p}<=0.2$ level in the simple regression models were included in the multiple regression model. Regression analyses were performed separately for all children and for children undergoing cycloplegic refraction $(608 / 882=68.9 \%)$. Statistical analysis was done using a commercially available software package (Stata 13.1, StataCorp, College Station TX, USA). 


\section{Results}

A total of 276 teachers (mean age 37.9 [8.51] years, $67.8 \%$ female) participated in this study, among whom 145 (52.7\%) reported owning glasses, and 44 (19.1\%) had presenting VA in the better-seeing eye $<=6 / 12$. Among teachers with uncorrected VA $<=6 / 12$ in either eye, $91.5 \%(86 / 94)$ had distance glasses, and $54.1 \%(46 / 86)$ of these indicated they routinely wore them. (Table 1)

Table 1. Characteristics of teachers participating in a study of purchase and wear of children's glasses in rural China $(\mathrm{N}=\mathbf{2 7 6})$

\begin{tabular}{|c|c|c|}
\hline Teacher characteristic & Result & $\begin{array}{c}\text { Missing value } \\
\text { n (\%) }\end{array}$ \\
\hline Age (Years: mean (SD)) & $37.9(8.51)$ & $3(1.09)$ \\
\hline Female sex (n, \%) & $187(67.8)$ & $0(0.00)$ \\
\hline Yunnan residence $(\mathrm{n}, \%)$ & $100(36.2)$ & $0(0.00)$ \\
\hline Teaching experience (Years: n, \%) & & $2(0.72)$ \\
\hline $1-10$ & $81(29.6)$ & \\
\hline $11-20$ & $95(34.7)$ & \\
\hline$>=21$ & $98(35.8)$ & \\
\hline Presenting visual acuity (Better-seeing eye $\left.{ }^{\dagger}\right)(\mathrm{n}, \%)$ & & $45(16.3)$ \\
\hline$<=6 / 12$ & $44(19.1)$ & \\
\hline$>6 / 12$ & $187(80.9)$ & \\
\hline Self-reported glasses ownership (n, \%) & & $1(0.36)$ \\
\hline Yes & $145(52.7)$ & \\
\hline No & $130(47.3)$ & \\
\hline $\begin{array}{l}\text { Self-reported distance glasses wear among those with } \\
\text { uncorrected visual acuity in either eye }<=6 / 12(n=86)(n, \%)\end{array}$ & & $1(1.16)$ \\
\hline Rarely worn & $12(14.1)$ & \\
\hline Worn when studying or working & $27(31.8)$ & \\
\hline Routinely worn & $46(54.1)$ & \\
\hline Self-reported distance glasses wear among those with & & $1(3.57)$ \\
\hline
\end{tabular}




\begin{tabular}{lc}
\hline presenting visual acuity in better-seeing eye $<=\mathbf{6 / 1 2}(\mathbf{n}=\mathbf{2 8})$ & \\
$(\mathbf{n ,} \boldsymbol{\%})$ & $8(29.6)$ \\
$\quad$ Rarely worn & $13(48.2)$ \\
Worn when studying or working & $6(22.2)$ \\
\hline Routinely worn &
\end{tabular}

SD: Standard Deviation

${ }^{\dagger}$ The eye with better uncorrected visual acuity

A total of 882 children with correctable refractive error (mean aged 10.6 [0.95] years,

$45.5 \%$ male) at 138 schools took part, among whom only $104(11.8 \%)$ were wearing

glasses at baseline. Among all children, 311 (35.3\%) had uncorrected visual acuity

$<6 / 18$ in the better-seeing eye, and $220(25.0 \%)$ believed that wearing glasses harms the

vision. Other baseline characteristics of children and their families are summarized in

Table 2.

Table 2. Baseline characteristics of 882 children with correctable refractive error participating in a study of purchase and wear of glasses in rural China. (Number, \%, unless otherwise indicated)

\begin{tabular}{lc}
\hline Characteristics & Results \\
\hline Age (Years, mean (SD)) & $10.6(0.95)$ \\
Male sex & $401(45.5)$ \\
Wearing glasses at baseline ${ }^{\dagger}$ & $104(11.8)$ \\
Yunnan residence & $183(20.8)$ \\
Spherical equivalent refractive error (Diopters) & \\
\hline
\end{tabular}




$$
<=-2.00
$$

$>-2$ to $-0.5(-2,0.5]$

$>-0.5$ to $0.5(-0.5,0.5]$

At least one parent wears glasses

Self-reported study time each day after school

$$
\begin{aligned}
& <0.5 \mathrm{hr} \\
& 0.5-1 \mathrm{hr} \\
& >1 \mathrm{hr}
\end{aligned}
$$

Percentage of classroom teaching done on blackboard (As opposed to books at students' desks)? * 
All

$97(11.0)$

More than half

Half

Rarely

$161(18.3)$

None

$22(2.50)$

Family wealth, Median (Inter Quartile Range), USD

Bottom tercile ( $\mathrm{n}=283,32.2 \%)$

Middle tercile ( $\mathrm{n}=301,34.3 \%)$

Top tercile $(\mathrm{n}=294,33.5 \%)$

\section{Study group (Number of children [\%])}

Control

$257(29.1)$

Free glasses

$253(28.7)$

Free glasses $+\$ 15$ upgrade

$187(21.2)$

Free glasses $+\$ 30$ upgrade

$185(21.0)$

\footnotetext{
${ }^{\dagger}$ Defined as having glasses at school at baseline, having previously been told to bring them to school. $\$ 2$ missing values

$\S 4$ missing values

ॠ $1 \mathrm{USD}=6.5 \mathrm{RMB}$
}

Among teachers, 20.4\% (56/275) believed wearing glasses would worsen children's vision, $68.4 \%$ (188/275) felt traditional Chinese eye exercises could prevent myopia, 
and 55.0\% (151/275) thought that children with moderate degrees of myopia should not wear glasses. (Table 3) The majority of teachers $(140 / 275=50.9 \%)$ thought that glasses could not treat myopia or were uncertain, while only a very small minority $(3 / 275=1.09 \%)$ believed that excessive studying was a cause of myopia among children in their class. Majorities of teachers supported children wearing glasses in their classrooms $(242 / 273=88.6 \%)$ and reported actively reminding children in their classes to obtain glasses during the project $(256 / 275=93.1 \%)$. (Table 3$)$

Table 3. Teachers' Knowledge (Correct answers in parentheses), Practices and Attitudes about Children's Myopia and Glasses Wear $(\mathbf{N}=\mathbf{2 7 6})$.

\begin{tabular}{|c|c|}
\hline Variables & n (\%) \\
\hline \multirow{2}{*}{\multicolumn{2}{|c|}{$\begin{array}{l}\text { Eye exercises prevent myopia }{ }^{\dagger} \text { (Treated as False for purposes } \\
\text { of analysis) }\end{array}$}} \\
\hline & \\
\hline Very much agree & $49(17.8)$ \\
\hline Agree & $139(50.55)$ \\
\hline Indifferent & $68(24.7)$ \\
\hline Disagree & $19(6.91)$ \\
\hline Very much disagree & $0(0.00)$ \\
\hline \multicolumn{2}{|c|}{ Having myopia but not wearing glasses will negatively affect } \\
\hline \multicolumn{2}{|l|}{ learning ${ }^{\dagger}$ (True) } \\
\hline Very much agree & $82(29.8)$ \\
\hline Agree & $148(53.8)$ \\
\hline Indifferent & $31(11.3)$ \\
\hline Disagree & $13(4.73)$ \\
\hline Very much disagree & $1(0.36)$ \\
\hline Wearing glasses will wo & \\
\hline
\end{tabular}




\begin{tabular}{|c|c|}
\hline Very much agree & $10(3.64)$ \\
\hline Agree & $46(16.7)$ \\
\hline Indifferent & $88(32.0)$ \\
\hline Disagree & $124(45.1)$ \\
\hline Very much disagree & $7(2.55)$ \\
\hline \multicolumn{2}{|c|}{$\begin{array}{l}\text { There is no need for children with modest degrees of myopia to } \\
\text { wear glasses }{ }^{\dagger} \text { (False) }\end{array}$} \\
\hline Very much agree & $26(9.45)$ \\
\hline Agree & $125(45.5)$ \\
\hline Indifferent & $56(20.4)$ \\
\hline Disagree & $65(23.6)$ \\
\hline Very much disagree & $3(1.09)$ \\
\hline \multicolumn{2}{|l|}{ Myopia can be successfully treated with glasses ${ }^{\dagger}$ (True) } \\
\hline Very much agree & $17(6.18)$ \\
\hline Agree & $118(42.9)$ \\
\hline Indifferent & $82(29.8)$ \\
\hline Disagree & $56(20.4)$ \\
\hline Very much disagree & $2(0.73)$ \\
\hline Teacher’s knowledge score (points) ${ }^{\dagger,}$, mean (SD) & $15.5(2.23)$ \\
\hline \multicolumn{2}{|l|}{ Attitude towards students in my class wearing glasses ${ }^{\S}$} \\
\hline Support & $242(88.6)$ \\
\hline Not support & $31(11.4)$ \\
\hline \multicolumn{2}{|c|}{$\begin{array}{l}\text { Best way to manage a child's myopia problem? (Choose one } \\
\text { only) }{ }^{\dagger}\end{array}$} \\
\hline Wear glasses & $182(66.2)$ \\
\hline Use eye drops & $2(0.73)$ \\
\hline Perform eye exercises & $62(22.6)$ \\
\hline Eat a nutritious diet & $11(4.00)$ \\
\hline Use other medicines & $2(0.73)$ \\
\hline
\end{tabular}


Do Surgery

Other way
$4(1.45)$

$12(4.36)$

\section{Main reason for myopia among children in your class? (Choose}

one only) ${ }^{\dagger}$

Excessive study time

Watching television

Using other electronic devices (computers, games)

Insufficient light while reading

Genetic factors

Other reasons

Did you advise your students to obtain glasses? ${ }^{\dagger}$

Yes

No

$19(6.91)$

$\dagger 1$ missing value

$\$$ The total teacher’s knowledge score was sum score of five knowledge items with 5-level Likert scales, true statement items were reverse coded to make 1 [worst]-5[best]. The possible range was $5-25$.

$\S 3$ missing values

Families of 269/625 (43.0\%) of children accepted the offer of free glasses in the study (257 children in the Control group were not eligible to receive them), while families of 169/882 (19.2\%) of children had purchased glasses (either those offered as "upgrades" by the study, or outside the study) by the time of the endline examination. At this unannounced end-line examination, 205/867 (23.6\%) of children were observed wearing spectacles $(15 / 882=1.7 \%$ of children had been lost to follow-up. $)$

Table 4 shows teacher and child/family factors associated with acceptance, purchase 
and wear of children's glasses. Teacher factors associated with uptake and wear of glasses in either univariate or multivariate models included: believing wearing glasses harms children's vision (decreased purchase of glasses in the univariate model only: Relative Risk [RR] 0.65, 95\% CI 0.43, 0.98, $\mathrm{P}<0.05$ ); supporting students wearing glasses in class (increased glasses wear in the univariate model only: RR $2.20,95 \%$ CI $1.23,3.95, \mathrm{P}<0.01$ ) and advising children to obtain glasses (increased acceptance of free glasses in the univariate model RR 3.50, 95\% CI 1.43, 8.61, P $<0.01$, and in multivariate model RR 2.74, 95\% CI 1.29, 5.84, P $<0.01$ ); increased glasses wear in the univariate model only: RR 2.93, 95\% CI 1.45, 5.90, P < 0.01), but not teacher's ownership or wear of or knowledge about glasses. (Table 4) Additionally, having a teacher older than the median age of 37 significantly decreased children's observed wear of glasses: univariate model RR $0.68,95 \%$ CI $0.51,0.90, \mathrm{P}<0.01$, multivariate model RR 0.74, 95\% CI 0.57, 0.96, P $<0.05$; having a female teacher reduced acceptance of free glasses in the univariate model: RR $0.73,95 \%$ CI $0.55,0.95, \mathrm{P}<$ 0.05, while increasing purchase of glasses: univariate model RR $1.73,95 \%$ CI 1.08 , 2.75, P $<0.05$, multivariate model RR 2.20, 95\% CI 1.41, 3.43, P $<0.001$.

Child/family factors associated with spectacle uptake in multivariate models included Yunnan residence, where children were more likely both to accept free glasses (RR $1.42,95 \%$ CI $1.09,1.85, \mathrm{P}<0.05)$ and to purchase them (RR 1.75, 95\% CI 1.22, 2.51, P 
$<0.01$ ). Additionally, children with better uncorrected vision (univariate model RR 0.07, 95\% CI 0.03, 0.16, P < 0.001, multiple model RR 0.28, 95\% CI 0.11, 0.68, $\mathrm{P}<$ $0.01)$ were more likely not to be wearing glasses, and those wearing glasses at baseline (RR 2.68, 95\% CI 2.03, 3.54, $\mathrm{P}<0.001$ ) were more likely to be wearing glasses at endline. Being in the top tercile of family wealth (RR 1.45, 95\% CI 1.08, 1.95, P < $0.05)$ and studying $>1$ hour/day (RR $1.37,95 \%$ CI 1.01, 1.86, $\mathrm{P}<0.05)$ were associated with greater likelihood of wearing glasses at endline, though only in the univariate model (Table 4) 


\begin{tabular}{|c|c|c|c|c|c|c|}
\hline & & & \\
\hline & $\begin{array}{c}\text { Simple regression } \\
\text { RR } \\
(\mathbf{9 5 \%} \mathbf{C I})^{\S} \\
\end{array}$ & $\begin{array}{c}\text { Multiple regression } \\
\text { RR } \\
(95 \% \text { CI) }\end{array}$ & $\begin{array}{c}\text { Simple regression } \\
\text { RR } \\
(95 \% \mathrm{CI})^{\S} \\
\end{array}$ & $\begin{array}{c}\text { Multiple regression } \\
\text { RR } \\
(95 \% \mathrm{CI})\end{array}$ & $\begin{array}{c}\text { Simple regression } \\
\text { RR } \\
(95 \% \mathrm{CI})^{\S} \\
\end{array}$ & $\begin{array}{c}\text { Multiple regression } \\
\text { RR } \\
(95 \% \text { CI) } \\
\end{array}$ \\
\hline \multicolumn{7}{|l|}{$\underline{\text { Teacher factors }}$} \\
\hline $\begin{array}{l}\text { Teacher's age above median (37) } \\
\text { (below median as reference) }\end{array}$ & $0.76(0.58,1.00)$ & $0.87(0.69,1.10)$ & $1.11(0.79,1.55)$ & & $0.68(0.51,0.90)^{* * *}$ & $0.74(0.57,0.96)^{*}$ \\
\hline Female teacher & $0.73(0.55,0.95)^{*}$ & $0.85(0.67,1.08)$ & $1.73(1.08,2.75)^{*}$ & $2.20(1.41,3.43)^{* * * *}$ & $1.17(0.80,1.72)$ & \\
\hline $\begin{array}{l}\text { Teacher's presenting visual } \\
\text { acuity }<=6 / 12 \text { (Better-seeing eye) }\end{array}$ & $0.94(0.62,1.42)$ & & $1.28(0.81,2.00)$ & & $0.80(0.48,1.32)$ & \\
\hline Teacher owns glasses & $1.04(0.79,1.37)$ & & $1.10(0.77,1.56)$ & & $0.97(0.70,1.34)$ & \\
\hline $\begin{array}{l}\text { Teacher wears glasses routinely in } \\
\text { class }\end{array}$ & $0.79(0.57,1.09)$ & $0.87(0.62,1.21)$ & $0.86(0.58,1.29)$ & & $0.81(0.54,1.20)$ & \\
\hline \multicolumn{7}{|l|}{$\begin{array}{l}\text { Teacher believes wearing glasses } \\
\text { harms children's vision (Disagree as } \\
\text { reference) }\end{array}$} \\
\hline Agree & $0.78(0.53,1.14)$ & $0.78(0.56,1.09)$ & $0.65(0.43,0.98)^{*}$ & $0.99(0.59,1.65)$ & $0.94(0.59,1.49)$ & \\
\hline Indifferent & $0.80(0.60,1.06)$ & $0.87(0.69,1.09)$ & $1.09(0.75,1.60)$ & $1.48(0.99,2.22)$ & $1.07(0.72,1.60)$ & \\
\hline \multicolumn{7}{|l|}{$\begin{array}{l}\text { Teacher's attitude towards students } \\
\text { wearing glasses in class }\end{array}$} \\
\hline Supports & $1.70(0.86,3.34)$ & $1.41(0.90,2.22)$ & $1.62(0.88,2.95)$ & $1.54(0.84,2.84)$ & $2.20(1.23,3.95)^{* * *}$ & $1.36(0.72,2.55)$ \\
\hline Not support & Reference & Reference & Reference & Reference & Reference & Reference \\
\hline $\begin{array}{l}\text { Teacher advised children to } \\
\text { purchase glasses (Never advised as } \\
\text { reference) }\end{array}$ & $3.50(1.43,8.61)^{* * *}$ & $2.74(1.29,5.84)^{* *}$ & $1.42(0.77,2.60)$ & & $2.93(1.45,5.90)^{* * *}$ & $2.34(0.99,5.56)$ \\
\hline
\end{tabular}




\section{$\underline{\text { Student factors }}$}

Age (Years)

Male sex

Wearing glasses at baseline \#

\section{Yunnan residence (versus}

Guangdong)

Spherical equivalent refractive error

(Diopters), $(>-0.5$ to 0.5 as reference)

$$
\begin{aligned}
& <=-2.00 \\
& >-2 \text { to }-0.5(-2,0.5] \\
& >0.5
\end{aligned}
$$

Uncorrected VA in eye with better vision (Decimal)

Only child in family (versus $>1$ child)

One or both parents with $\geq 12$ years of education (versus $<12$ year)

Both parents away from the home the majority of time (versus lived at home)
$0.99(0.89,1.10)$

$0.89(0.74,1.06)$

$0.93(0.79,1.10)$

$1.00(0.71,1.40)$

$1.77(1.36,2.32)^{* * *}$

$1.42(1.09,1.85)^{*}$

$1.45(0.77,2.73)$

$1.22(0.62,2.41)$

$0.33(0.04,2.54)$

$0.72(0.40,1.30)$

$1.01(0.69,1.47)$

$1.19(0.86,1.65)$

$0.81(0.60,1.08)$
$0.91(0.79,1.06)$

$0.82(0.62,1.07)$

$0.81(0.62,1.06)$

$0.63(0.38,1.04)$

$1.75(1.22,2.51) * *$
$0.89(0.79,1.01)$

$0.92(0.71,1.20)$

$4.66(3.69,5.88) * * *$

$1.17(0.75,1.83)$
$0.90(0.781 .04)$

\section{$2.68(2.03,3.54) * * *$}

$3.11(1.50,6.45) * *$

$1.11(0.54,2.29)$

$1.31(0.63,2.70)$ $0.95(0.48,1.89)$

$3.37(1.38,8.26) * *$ $1.66(0.77,3.57)$

$0.07(0.03,0.16) * * *$ $0.28(0.11,0.68)^{* *}$

$1.29(0.96,1.74)$

$0.84(0.65,1.09)$

$1.33(1.05,1.70) *$

$1.12(0.90,1.40)$

$0.65(0.44,0.96) *$ 


$$
\begin{aligned}
& 0.5-1 \mathrm{hr} \\
& >1 \mathrm{hr}
\end{aligned}
$$

$\begin{array}{ccc}1.00(0.80,1.24) & 0.99(0.81,1.20) & 0.92(0.68,1.24) \\ \mathbf{0 . 7 0}(\mathbf{0 . 5 4}, \mathbf{0 . 9 2}) * * & \mathbf{0 . 7 4}(\mathbf{0 . 5 8}, \mathbf{0 . 9 5}) * & 1.26(0.86,1.86)\end{array}$

$1.13(0.84,1.52)$

$1.03(0.79,1.33)$

$0.70(0.54,0.92) *$

$0.74(0.58,0.95)$

$1.37(1.01,1.86)^{*}$

Classroom teaching on the blackboard (less than half as reference)

Half of teaching

$1.02(0.75,1.38)$

$1.00(0.66,1.51)$

$1.17(0.83,1.64)$

$1.11(0.79,1.57)$

$1.09(0.67,1.76)$

$1.22(0.83,1.79)$

Family wealth (Bottom tercile as reference)

Middle tercile

$0.80(0.62,1.03)$

$0.98(0.79,1.22)$

$1.15(0.83,1.60)$

$1.38(0.98,1.95)$

$1.04(0.77,1.39)$

Top tercile

$0.74(0.59,0.92) * *$

$0.82(0.67,1.02)$

$1.20(0.85,1.70)$

$1.45(1.08,1.95) *$

$1.06(0.79,1.41)$

Not included

Reference

$1.06(0.76,1.49)$

$0.85(0.53,1.34)$

\section{Reference}

$0.54(0.34,0.85)^{* *}$

$0.90(0.56,1.45)$

$0.88(0.53,1.46)$
Reference

$0.56(0.36,0.86) * *$

$1.14(0.75,1.73)$

$0.86(0.56,1.31)$

\section{Reference}

$1.59(0.98,2.58)$

$1.17(0.70,1.97)$

$0.88(0.46,1.67)$

\section{Reference}

$1.41(0.93,2.15)$

$1.16(0.76,1.77)$

$0.95(0.54,1.65)$

Table 4. Effect of potential student and teacher factors on acceptance, purchase prior to endline and wear of glasses at endline adjusting for cluster effect within school ( $\mathrm{N}=\mathbf{8 8 2}$ ) (Significance is indicated by* $\mathbf{P}<0.05, * * \mathbf{P}<0.01, * * * \mathbf{P}<0.001$. The data are adjusted for group assignment in the parent trial) 
${ }^{\dagger}$ Among students accepting Free and Free+ Upgrade glasses from study at endline.

$\$ 15$ students who were lost to follow up didn’t have outcome data.

$\S$ Only one predictor was included in the model.

ๆ Variables with $\mathrm{P}<=0.2$ were included in multiple regression model. 32/625 (5.12\%) students for acceptance of free spectacles, $24 / 882$ (2.72\%) for purchase of spectacles and $37 / 882$ (4.20\%) for endline glasses wear were excluded in the multiple regression analysis due to missing values.

\# Defined as having glasses at school at baseline, having previously been told to bring them to school. 


\section{Discussion}

The current study highlighted a number of gaps in teachers' knowledge about children's vision and glasses wear. Majorities of teachers believed that glasses wear should be avoided or was harmful to children's vision, though recent evidence from randomized trials ${ }^{4}$ suggests that this is not true, and that eye exercises prevent myopia, though little reliable evidence ${ }^{16}$ exists in support of this. Nonetheless, a very large proportion of teachers reported both supporting and directly recommending that children obtain glasses, and these views and actions were significantly associated with glasses acceptance and wear by children.

Our own randomized trials $\mathrm{s}^{12}$ and reports from others ${ }^{17,18}$ have suggested that interventions relying wholly or in part on teachers can be effective in increasing spectacle use among children. Little information, however, exists on the impact of teacher knowledge and attitudes towards glasses wear on student use of spectacles in the more typical situation where teachers are not actively being asked to promote wear, as in the current study. Other studies have attempted to elucidate teacher and parent attitudes towards children's use of glasses in China $^{9}$ and elsewhere ${ }^{19,20}$, though without examining the impact of these attitudes on actual wear. Our finding in the current study that the recommendation of teachers significantly influenced acceptance of free glasses, even when adjusting for child/family factors, suggests that teachers 
play an important role in determining the behavior of children and families in this setting, even outside of teacher incentive programs.

Though over half of teachers reported owning glasses, among teachers who owned distance glasses, only half of indicated that they wore them regularly, and one in five teachers had presenting visual acuity $<=6 / 12$ in either eye. These are consistent with findings from urban Indonesia, ${ }^{21}$ where an even larger proportion of teachers had either uncorrected distance refractive error $(36 \%)$ or uncorrected presbyopia $(41 \%)$. In the current setting, neither teacher's ownership nor wear of glasses was significantly associated with any of the variables concerning children's acceptance of spectacles. Despite the lack of a direct effect on children's wear, the high proportion of teachers with poor visual acuity reported in China and Indonesia ${ }^{21}$ suggests that studies of the impact of visual acuity on teaching effectiveness may be warranted in these settings, particularly in view of trial evidence that correction of children's refractive error significantly improves their educational outcomes. ${ }^{5}$ If children who see poorly learn poorly, it is not difficult to imagine that visually impaired teachers may also teach poorly.

Significant, though not always consistent, associations were seen between age and gender on the one hand and children's acceptance of glasses on the other. Older teachers were less effective in promoting glasses acceptance, while female teachers 
had higher rates of spectacle purchase and lower rates of acceptance of free glasses in their classes. The implications for glasses promotion programs may be less significant than our findings on the importance of teachers' attitudes, in that the latter are subject to change through interventions, while age and gender are not.

We found it unexpected that children who studied more were less willing to accept free glasses, and would have supposed that the opposite might be true. We expect this indicates that families of such children preferred to purchase upgrade glasses, rather than accepting free ones, which is consistent with our findings. We did not, however, find that the tendency of children who studied more being less likely to accept free glasses could be explained by a greater likelihood of glasses ownership at baseline (data not shown.)

Strengths of the current study include the large numbers of schools enrolled, and their selection at random in both rich and poor provinces of China, where lack of use of glasses is a major public health problem; the relatively rich data on teachers' knowledge and attitudes; and the high rates of follow-up among children (98.3\%) and carefully-measured endpoints on their acceptance and wear of glasses. Limitations must also be acknowledged: we relied on teachers to report whether or not they encouraged children to obtain glasses. Further, only 8 counties were enrolled in two provinces, and thus application of these results to other areas must be made with 
caution.

Nonetheless, this is among the few studies of the impact of teachers' knowledge, attitudes and behaviors on children's use of glasses in China or elsewhere. It adds to a growing body of literature underscoring the important role of teachers in solving China's school refractive error problem through accurate vision screening ${ }^{11}$ and successful promotion of spectacle use. ${ }^{12}$ 


\section{Acknowledgements}

This work was supported by Zhongshan Ophthalmic Center, State Key Laboratory of

Ophthalmology, Division of Preventive Ophthalmology, Sun Yat-sen University,

Guangzhou, China; The Fred Hollows Foundation; Orbis International; US Agency

for International Development Children Blindness Program; Luxottica-China

(Shanghai); Essilor-China(Shanghai). 


\section{References}

1. Resnikoff S, Pascolini D, Mariotti SP, Pokharel GP. Global magnitude of visual impairment caused by uncorrected refractive errors in 2004. Bull World Health Organ 2008;86:63-70.

2. He M, Zeng J, Liu Y, Xu J, Pokharel GP, Ellwein LB. Refractive error and visual impairment in urban children in southern china. Invest Ophthalmol Vis Sci 2004;45:793-9.

3. He M, Huang W, Zheng Y, Huang L, Ellwein LB. Refractive error and visual impairment in school children in rural southern China. Ophthalmology 2007;114:37482.

4. Ma X, Congdon N, Yi H, et al. Safety of Spectacles for Children's Vision: A Cluster-Randomized Controlled Trial. Am J Ophthalmol 2015;160:897-904.

5. Ma X, Zhou Z, Yi H, et al. Effect of providing free glasses on children's educational outcomes in China: cluster randomized controlled trial. BMJ 2014;349:g5740.

6. Wang X, Yi H, Lu L, et al. Population prevalence of need for spectacles and spectacle ownership among urban migrant children in eastern China. JAMA Ophthalmol 2015;133:1399-1406.

7. Zhou Z, Zeng J, Ma X, et al. Accuracy of rural refractionists in western China. Invest Ophthalmol Vis Sci 2014;55:154-61.

8. Zhang M, Lv H, Gao Y, et al. Visual morbidity due to inaccurate spectacles among 
school children in rural China: the See Well to Learn Well Project, report 1. Invest Ophthalmol Vis Sci 2009;50:2011-7.

9. Li L, Lam J, Lu Y, et al. Attitudes of Students, Parents, and Teachers Toward Glasses Use in Rural China. Arch Ophthalmol 2010;128:759-65.

10. Li L, Song Y, Liu X, et al. Spectacle acceptance among secondary school students in rural China: the Xichang Pediatric Refractive Error Study (X-PRES)--report 5. Invest Ophthalmol Vis Sci 2008;49:2895-902.

11. Sharma A, Li L, Song Y, et al. Strategies to improve the accuracy of vision measurement by teachers in rural Chinese secondary schoolchildren Xichang Pediatric Refractive Error Study (X-PRES) report no 6. Arch Ophthalmol 2008;128:1434-40.

12. Yi H, Zhang $\mathrm{H}$, Ma X, et al. Impact of free glasses and a teacher incentive on children's use of eyeglasses: a cluster-randomized controlled trial. Am J Ophthalmol 2015;160:889-96.e1.

13. Wang X, Congdon N, Ma Y, et al. Cluster-randomized controlled trial of the effects of free glasses on purchase of children's glasses in China: the PRICE (Potentiating Rural Investment in Children's Eyecare) study. PLoS One 2017;12:e0187808.

14. List of Chinese administrative divisions by GDP per capita. Accessed March 2016. Available from: https://en.wikipedia.org/wiki/List_of_Chinese_administrative_divisions_by_GDP_per _capita. 
15. Congdon NG, Patel N, Esteso P, et al. The association between refractive cutoffs for spectacle provision and visual improvement among school-aged children in South Africa. Br J Ophthalmol 2008;92:13-8.

16. Lin Z, Vasudevan B, Jhanji V, et al. Eye exercises of acupoints: their impact on refractive error and visual symptoms in Chinese urban children. BMC Complement Altern Med 2013;13:306.

17. Ethan D, Basch CE, Platt R, Bogen E, Zybert P. Implementing and evaluating a school-based program to improve childhood vision. J Sch Health 2010;80:340-5; quiz 368-70.

18. Kodjebacheva G, Maliski S, Yu F, Oelrich F, Coleman AL. Decreasing uncorrected refractive error in the classroom through a multifactorial pilot intervention. $J$ Sch Nurs 2014;30:24-30.

19. Kodjebacheva GD, Maliski S, Coleman AL. Use of eyeglasses among children in elementary school: perceptions, behaviors, and interventions discussed by parents, school nurses, and teachers during focus groups. Am J Health Promot 2015;29:324-31. 20. Dudovitz RN, Izadpanah N, Chung PJ, Slusser W. Parent, Teacher, and Student Perspectives on How Corrective Lenses Improve Child Wellbeing and School Function. Matern Child Health J 2016;20:974-83.

21. Ehrlich JR, Laoh A, Kourgialis N, et al. Uncorrected refractive error and presbyopia among junior high school teachers in Jakarta, Indonesia. Ophthalmic 
Epidemiol 2013;20:369-74. 